\title{
PROFESSIONAL, ACADEMIC AND INDUSTRIAL DEVELOPMENT NEEDS: A COMPETENCY MAPPING AND EXPERT OPINION REVIEW
}

\author{
Srinath PERERA ${ }^{1}$ 夰, John PEARSON ${ }^{2}$, Damilola EKUNDAYO ${ }^{3}$ and Lei ZHOU ${ }^{4}$ \\ ${ }^{1}$ Northumbria University, Ellison Place, Newcastle upon Tyne NE1 8ST, United Kingdom \\ E-mail: srinath.perera@northumbria.ac.uk \\ 2 Northumbria University, Newcastle upon Tyne NE1 8ST, United Kingdom \\ E-mail: john.pearson@northumbria.ac.uk \\ ${ }^{3}$ Northumbria University, Newcastle upon Tyne NE1 8ST, United Kingdom \\ E-mail: damilola.ekundayo@northumbria.ac.uk \\ ${ }^{4}$ Northumbria University, Newcastle upon Tyne NE1 8ST, United Kingdom \\ E-mail:lei.zhou@northumbria.ac.uk
}

Received 10 May 2012; accepted 5 January 2013

\begin{abstract}
There is a tripartite pull from academics, industry and professional bodies on the development needs of the Quantity Surveyor (QS). At best, there is scope for misunderstandings between the stakeholders as to what is being required and what is being achieved. At worst there may be actual gaps in the education and/or training being offered and some discrepancies between the levels of attainment. This research sought to review the Royal Institution of Chartered Surveyors (RICS) QS competencies and their application in the delivery of QS degree programmes. The changing development needs of QSs who satisfy the aspirations of industrial, professional and academic stakeholders were investigated through content analysis of the views of an expert forum consisting of relevant stakeholders and a series of competency mapping case studies. The study revealed that there are considerably different standards right across the RICS accredited QS programmes with respect to coverage of competencies. It is concluded that there is no standard benchmark in achieving competencies and it is open to individual interpretation. Further research in the development of a Graduate Competency Threshold Benchmark is suggested to align the disparate views of the stakeholders to accommodate changing development needs.
\end{abstract}

KEYWORDS: Competency mapping; Graduate quantity surveyor; QS degree programmes; RICS QS competencies; Stakeholders

REFERENCE to this paper should be made as follows: Perera, S., Pearson, J., Ekundayo, D. and Zhou, L. (2013) Professional, academic and industrial development needs: A competency mapping and expert opinion review, International Journal of Strategic Property Management, 17(2), pp. 143-160.

\section{INTRODUCTION}

Quantity Surveying is the profession that is well established in the British Commonwealth as being responsible for the management of cost and contracts in the construction industry (RICS, 1971, 1983; Male, 1990; Pheng and Ming, 1997; Bowen et al., 2008; Ling and
Chan, 2008). The profession is also known as Construction Economics in Europe and Cost Engineering in the Americas and parts of Asia (Rashid, 2002; Pathirage and Amaratunga, 2006; Smith, 2009). The academic, professional and training needs of Quantity Surveyors are pulled by three different stakeholders in three different directions (Figure 1). Academics are 


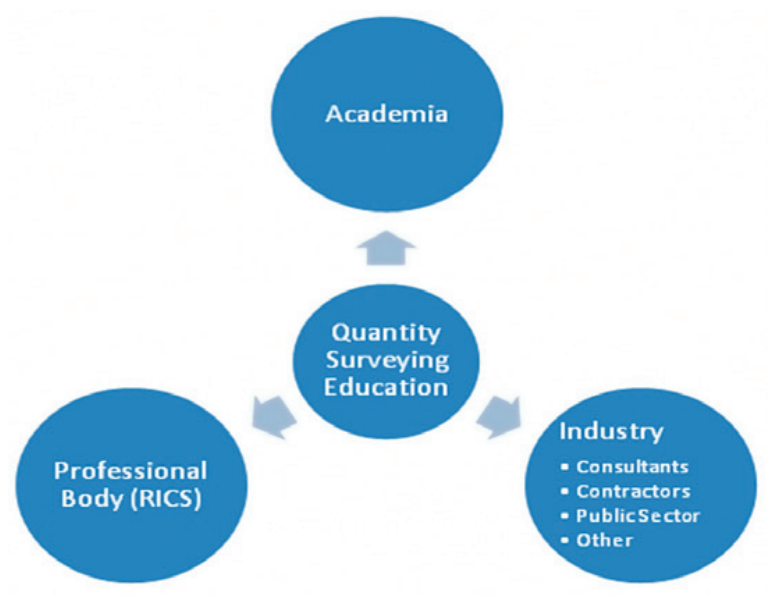

Figure 1. Key stakeholders influence on quantity surveying education

interested in producing a rounded graduate with the basic foundation of knowledge for further development whereas professional bodies are interested in graduates who can be progressed to full professional status through the achievement of the required core competencies (RICS, 2009a and 2009b; Perera and Pearson, 2011). The industry is looking for a graduate who can straight away contribute both to the daily functions of business activity and to its growth. Hence, there is a tripartite pull on the development needs of the Quantity Surveying Graduate. The present education system of the Quantity Surveyor does not recognise these multi-directional needs and hence often produces a graduate whom the industry sees as not fulfilling their requirements (Wong et al., 2007; Lee and Hogg, 2009; Perera and Pearson, 2011). This leads to many problems, with greater levels of employer and graduate dissatisfaction and obstacles to early career development of the QS graduate.

These conflicting concerns have long fuelled the "education versus training" debate and some conflict between Educators and Employers through which the RICS steers a sometimes difficult path. On the one hand it sends messages to the universities that it wishes to see programmes which lean more towards the "academic" rather than the "technical", whilst on the other hand it sends messages to employers that they should accept graduates issuing from its accredited degree programmes as being appropriately qualified to take positions at higher than technician grade (for which the RICS itself has a specific training route via the HND/Foundation Degree). This can create ambiguities and wrong impressions to the industry, creating conflicts in expectations. For its own part, the RICS has created a set of Core Competencies which, if they are to be fully achieved by candidates for membership, requires active cooperation between the academic sector (providers of basic subject knowledge and certain academic skills) and the industrial sector (providers of practical skills training) through the operation of their business.

\subsection{Current needs of quantity surveying graduates}

Significant growth in undergraduate level education of Quantity Surveyors stems from the late 1960's and early 1970's with the switch from Diplomas in Quantity Surveying, firstly to Ordinary degrees and, within a few years, to Honours Degrees. From the 1971 RICS report "The Future Role of the Quantity Surveyor" (RICS, 1971) identifying specific competencies at the time, the profession began to evolve rapidly and in 1983 a further report was produced, "The Future of the Chartered Quantity Surveyor" (RICS, 1983) as if to further consolidate the professional status of the QS. Just over twenty years ago, with the publication of the document "QS2000" (Davis Langdon and Everest, 1991) there was recognition of a number of forces acting on the QS profession, highlighting both the changes to the client body and to the construction industry (Fan et al., 2001a, 2001b; John, 2002; Fellows et al., 2003; Rick, 2005; Cartlidge, 2006; Ling and Chan, 2008; Senaratne and Sabesan, 2008; Maidin and Sulaiman, 2011).

Both the RICS and the educational sector show similarities in their lack of appreciation of the specific requirements industry may have 
of its newly graduated student members. At the same time the industry does not seem to appreciate that a graduate is a person with higher intellectual capacity to rapidly further develop their professional skills and technical knowledge once in employment (Perera, 2006; Lee and Hogg, 2009; Simpson, 2010). This conflict and lack of alignment of industry, academic and professional perspectives create a barrier to the development of the profession as well as the career development of the graduate Quantity Surveyor.

Added to this is a more fundamental failure on the part of all parties to appreciate the dynamics of the market sector. The majority of new graduates appear to be entering more nontraditional quantity surveying routes (Perera, 2006; Perera and Pearson, 2011). It has been shown both through research (Perera, 2006) and through records of 1st destination Surveys (UNN Returns, 2001-2008) that a large majority of new graduates find employment not in Private Consultancy Practice (PQS) or the Public Sector, as was the case until the mid 1980's, but with Main Contracting and specialised subcontracting organisations. Perera (2006) shows that in the University of Ulster more than $80 \%$ of graduates either seek employment or prefer to be employed in the nonPQS sectors of the industry. The situation is very similar in many other universities in the UK. Feedback from Assessment of Professional Competence (APC) workshops has noted a certain Private Practice bias within the presentation of advice, and indeed there is feedback at university level suggesting this. Much of the academic content and the structure of the RICS itself would both seem directed at those employed in the PQS and Government Sector, paying less attention to the skills inherent in the role of the Contractor's Surveyor (Simpson, 2010). For their part, those engaged in developing Quantity Surveying within the construction sector may see this as another barrier to cooperating with the RICS when required. This is evident from the fact that RICS membership does not grow in the same proportion to the growth in Quantity Surveying student numbers (Perera, 2006). The emergence of Commercial Management (Walker and Wilkie, 2002; Lowe and Leiringer, 2006) as a distinct discipline encompassing the role of the contractor Quantity Surveyor is a fact that the RICS should consider in detail in its future development of career paths for the Quantity Surveyor. Leading Quantity Surveying professional bodies the world over have already begun to recognise these developments and trends. For example, recently the Australian Institute of Quantity Surveyors (AIQS) established a separate pathway for contractors' Quantity Surveyors for completing professional qualification.

\subsection{RICS assessment of professional competence}

The competence-based education initially started in nursing education in the 1970s (Trivett, 1975; Ewens, 1979; Cowan et al., 2007) and gained popularity in many other disciplines in formal and informal education and training all around the world over the last forty years (Mole et al., 1993; Meyer and Semark, 1996). Professional accreditation bodies in the built environment have also been advocates of a competency-based approach (Newton, 2009).

The entry of graduates and others into any professional group of the Royal Institution of Chartered Surveyors (RICS) as fully qualified Chartered surveyors comes only after they have successfully passed the Assessment of Professional Competence (APC). This is true of the Quantity Surveyor, the specific subject of this study, as much as for any other. Key to this is the demonstration, by the candidate, of their having attained certain competencies determined by the Education and Membership Board of RICS. In the case of the graduate, these competencies will have been acquired both through their formal university education and the workplace training which they have received, whether as part time students in employment or during a work placement. In 
either case, the applicant will have undertaken a period of full time employment beyond graduating, further adding to the in-service training element of their overall skills profile.

It will be appreciated that there is a balance to be struck between the level and type of competence which should be expected, and can be achieved, in the universities and that which arises out of exposure to experience only available within the workplace. To some extent the two must be complimentary, as they should be, and it has emerged over the years that both Academia and Industry have certain expectations of one another, rightly or wrongly, as to what the other can and will achieve as a vehicle for graduate learning. These last are encapsulated, for some, in the arguments within the "education versus training" debate that has dogged the relationship for as many years as formal Quantity Surveying education has existed. From the above it will be seen that, at best, there is scope for misunderstandings between the stakeholders as to what is being required and what is being achieved. At worst there may be actual gaps in the education and/ or training being offered and received or, at least, some discrepancies between the levels of attainment.

In summary, it is suggested that the present education system of the Quantity Surveyor does not recognise the multi-directional needs of the Quantity Surveyor and hence often produces a graduate whom the industry sees as not fulfilling their requirements. A further factor in the willingness on the part of the Industry to accept and train new graduates must be resource constraints born of the financial insecurity of the current economic recession, and being experienced severely by existing Members who might otherwise be more willing to accept the risks and responsibilities of employing and training new recruits. This paper is aimed at investigating the changing developmental needs of Quantity Surveyors who satisfy the aspirations of industrial, professional and academic stakeholders through the analysis of the views of an expert forum consisting of academics, industry and profes- sional body representatives. The research also sought to review competencies and their application in the delivery of QS programmes by mapping all 24 RICS QS competencies against curricular for four RICS accredited QS Honours degree programmes reported as four case studies to provide a full picture of the extent of coverage of competencies in the programmes accredited by the RICS.

\section{RESEARCH METHODOLOGY}

The research was carried out in three distinct data gathering phases culminating in data analysis and reporting. The key stages and process are detailed below.

\subsection{Review}

A detailed literature review was carried out to identify the RICS QS competencies and their interpretation.

\subsection{Competency mapping case studies}

A detailed competency mapping exercise was carried out based upon four RICS accredited quantity surveying programmes offered by four leading universities. This involved mapping RICS QS competencies to the individual module specifications of the respective QS programmes. These are referred to as mapping case studies.

\subsection{Expert forum}

This was the catalyst for the identification of key issues related to academia, industry and the RICS. An expert forum consisting of ten specialists was established. A series of interviews were carried out firstly to identify key issues and subsequently these were used to verify the findings of the competency mapping case studies. The forum comprised three academics (programme leaders), three consultant or project quantity surveyors (PQS), three contractor or commercial quantity surveyors (CQS) and one RICS representative (member of the RICS Education and Qualification Standards). 


\subsection{Analysis and survey results}

The content analysis of the interviews conducted and the competency mapping case studies provided a detailed account of the primary areas of investigation listed below:

1. RICS Quantity Surveying Competencies.

2. Role of the Quantity Surveyors \& Developments.

3. Quantity Surveying Education.

4. Modes of study \& placement.

5. RICS Routes of Membership \& Training.

6. Role of the RICS.

The RICS QS competencies were analysed in two different ways:

1. Mapping competencies to RICS accredited programme curricular.

2. Establishing the expected level of achievement of competencies by graduate quantity surveyors.

The outcomes related to each of these aspects are discussed in detail in the following sections.

\section{RICS QUANTITY SURVEYING COMPETENCIES}

\subsection{RICS QS competency requirements}

The RICS Competencies are arranged into three groupings, depending upon their perceived relevance to the Role of the Quantity Surveyor:

1. Mandatory Competencies: personal, interpersonal and professional practice and business skills common to all pathways [into membership] and compulsory for all candidates.

2. Core Competencies: primary skills of the candidate's chosen [RICS] pathway.

3. Optional Competencies: selected as an additional skill requirement for the candidate's chosen [RICS] pathway from a list of competencies relevant to that pathway. In most cases there is an element of choice.

The RICS distinguish between three possible levels of attainment in each of a range of competences when setting its requirements of those seeking membership. Briefly, these are as follows:

- Level 1: Knowledge (theoretical knowledge).

- Level 2: Knowledge and practical experience (putting it into practice).

- Level 3: Knowledge, practical experience and capacity to advise (explaining and advising).

There are 10 Mandatory competencies, 7 Core competencies and 7 Optional competencies (two only of these last to be selected by the candidate). The RICS stipulates that an APC candidate needs to achieve all Mandatory competencies at Level 2 or above, all Core competencies at Level 3 (except one not relevant to specialisation depending on employment in consulting or contracting practice which is at Level 2) and 2 Optional competencies at Level 2 or above.

\subsection{Competency mapping method}

The main method of competency mapping involved the use of a two dimensional matrix comprised of QS competencies on the $\mathrm{Y}$ - axis (vertical listing) and Programme specifications on the $\mathrm{X}$ - axis (horizontal listing). Each competency was subdivided into the three Levels (1 to 3). Figure 2 illustrates an example of this mapping matrix created as a protected spreadsheet form.

A detailed map scoring system (Table 1) was devised to enable indication of perceived levels of achievement of competencies through the evaluation of the individual module specifications pertaining to a programme.

Table 1. Map scoring system

\begin{tabular}{ll}
\hline Score criteria & Score \\
\hline Achieves small parts of a competency & 0.25 \\
Partially achieves a competency & 0.5 \\
Considerably achieves a competency & 0.75 \\
$\begin{array}{l}\text { Fully achieves a competency at respective } \\
\text { level }\end{array}$ & 1.00 \\
\hline
\end{tabular}

The respondents completing the form were required to make judgements as to what 


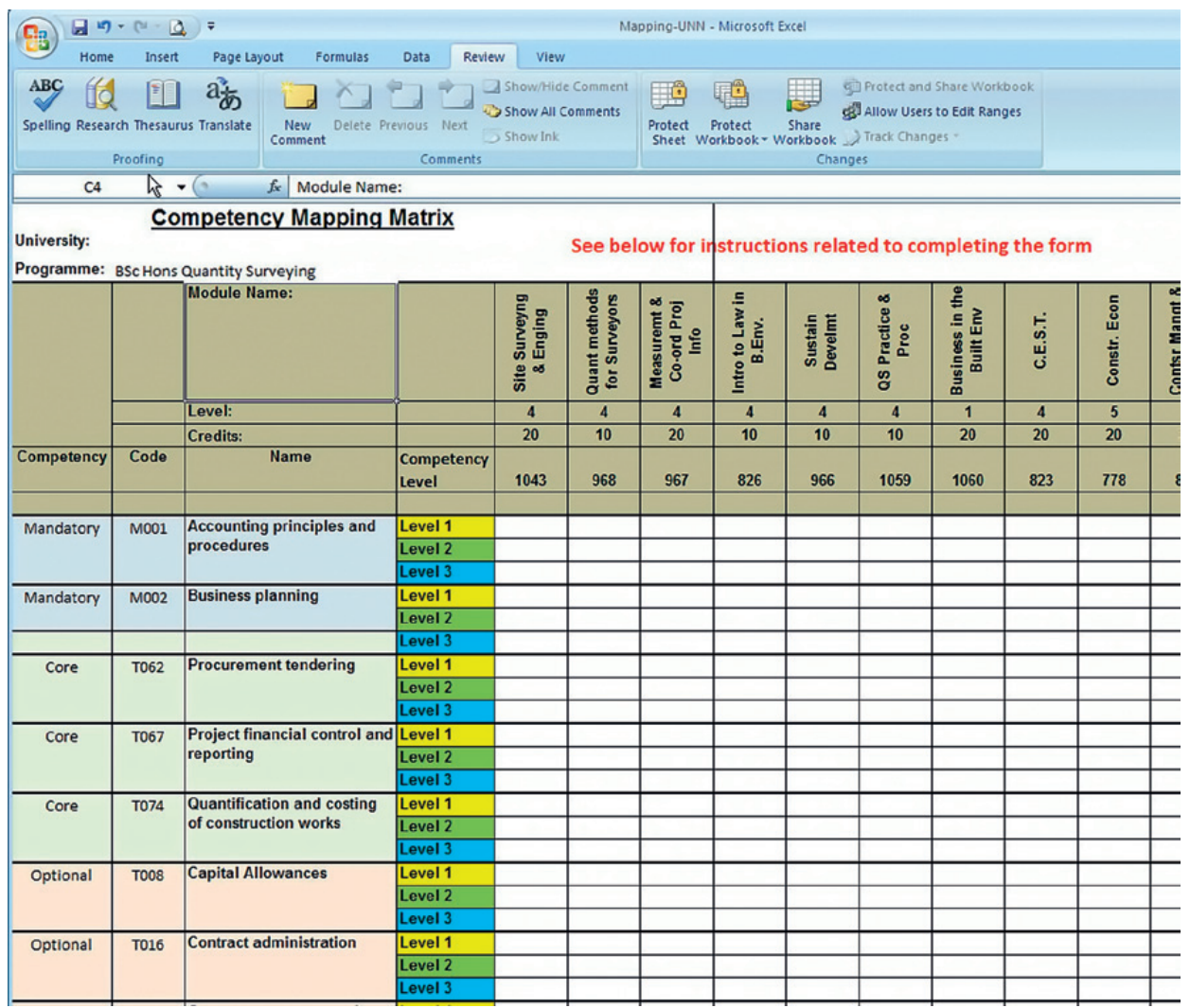

Figure 2. Competency mapping matrix form

amount of a competency at which Level (Levels 1,2 or 3 ) was achieved by each module of a programme.

\subsection{Mapping process}

Competency mapping to programme specifications was carried out in 3 stages:

1. Scoring the mapping matrix by the researchers.

2. Scoring the mapping matrix by programme directors of the respective programmes.

3. Consensus adjustment of scoring by the researchers to eliminate bias.

This three stage process established the final scores for competency mapping to programme specifications which were then used for the evaluation explained in this paper.

Programme Directors of the programmes selected as case studies were requested to complete the matrix form based on their judge- ment of the level of attainment of competencies. These case studies are referred to as Case study A, B, C, and D. Each was asked to allocate approximate scores, at each Level, as defined above, on a scale of 0.25 to 1.00 depending upon their estimation of the coverage they achieved for each of the RICS Mandatory, Core and Optional Competencies through delivery of the modules making up their Undergraduate Quantity Surveying Programme. Through this exercise total scores were achieved in respect of each of the above competencies for each University, together with totals relating to all Modules delivered. The scoring carried out by the programme directors was reviewed by the researchers through a discussion process to achieve a consensus view on individual module scores. The aim of this process was to eliminate individual bias of the scoring process and to achieve a reasonable degree of uniformity in the interpretation of scores. 
The last figure can be split to show total estimated delivery at each of the Levels 1, 2 and 3 .

There are three possible levels of analysis; the overall total coverage of all competencies for each University, the split between levels for each University and the individual University's actual coverage of specific competencies. These are each analysed in the following sections.

\section{COMPETENCES MAPPING CASE STUDIES}

\subsection{Overall total coverage of all competencies by universities}

There are some variation between the universities studied. Two Universities return total scores of 45 to 48 , as against the others who both score 37 , a difference between the two pairs of $25 \%$. This would seem to be a significant variance, given that all are offering broadly the same overall programme of delivery and assessment, within broadly similar timescales, and all leading to the same award.

Table 2. Total mapping score comparison

\begin{tabular}{llll}
\hline \multicolumn{4}{c}{ Total score } \\
\hline University & University & University & University \\
A & B & C & D \\
\hline 45.25 & 37.25 & 37.75 & 48 \\
\hline
\end{tabular}

\subsection{Inter-level split across universities}

The aggregated level of competency mappings for each university is evaluated in Table 3.

The main reason for the high level of variance between total coverage of competencies (Table 2) is the level of variance built in due to different volumes of coverage at Level 1. Both Level 2 \& 3 scores are very similar between universities. This suggests that they have a similar appreciation of the significance of the value of the higher two levels required of new graduates by the RICS. As would be expected, in all cases the total score for Level 1 far exceeds that for Level 2, and that for Level 2 is far in excess of that for Level 3. Level 3 hardly features at all, as one might expect, for it is a competency level only expected of candidates at the time they come to sit their APC, one year or more after graduating.

Table 3. Final scores by competency level

\begin{tabular}{|c|c|c|c|c|}
\hline \multicolumn{5}{|c|}{ Cumulative level score } \\
\hline $\begin{array}{l}\circlearrowright \\
\stackrel{d}{d} \\
\stackrel{\Delta}{\Theta}\end{array}$ & 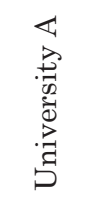 & 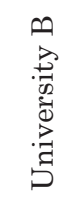 & 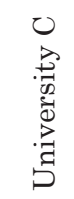 & 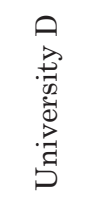 \\
\hline Level 1 & 32.5 & 27 & 26 & 37 \\
\hline Level 2 & 12.25 & 10 & 11 & 11.25 \\
\hline Level 3 & 0.50 & 0.50 & 0.25 & 0.50 \\
\hline
\end{tabular}

\subsection{Coverage of specific competencies by universities}

This section examines the coverage of competencies at the three different levels by the programmes studied. These are analysed separately for Mandatory, Core and Optional competencies.

\subsubsection{Coverage of mandatory competencies}

Mandatory competencies generally can be expected to be achieved at Level 1. Figure 3 shows how each university performed in coverage at Level 1.

The yellow benchmark line has been set at 1 to indicate sub standard coverage of competencies. A score of 1 or above indicates fully achieving a competency at the respective level. It is clear that there are many competencies (M001, M002, M003, M005, M006 and M008) that have not been adequately covered even at Level 1.

\subsubsection{Coverage of core competencies}

The coverage of the core competencies presents the most important analysis as these competencies are vital for the function of the quantity surveyor. Figure 4. Core competency mapping scores: Level 1 illustrates the coverage of Core competencies by universities.

When using a benchmark score of 1 all universities have achieved this for all competen- 


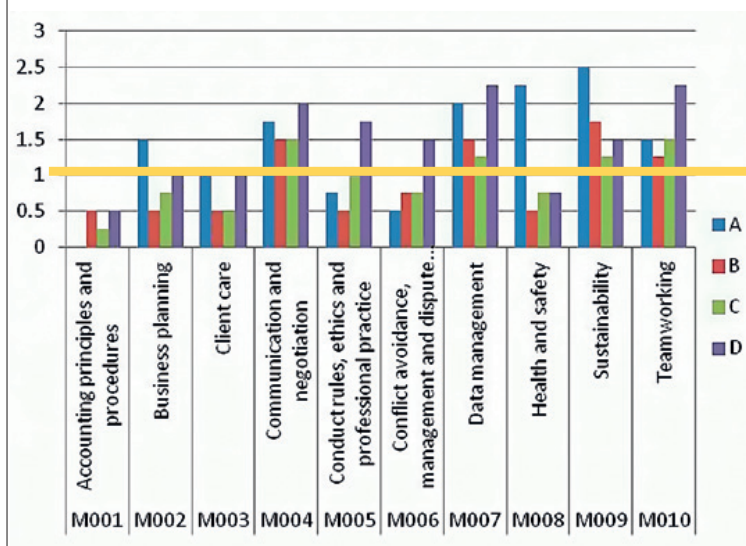

Figure 3. Mandatory competency mapping scores: Level 1

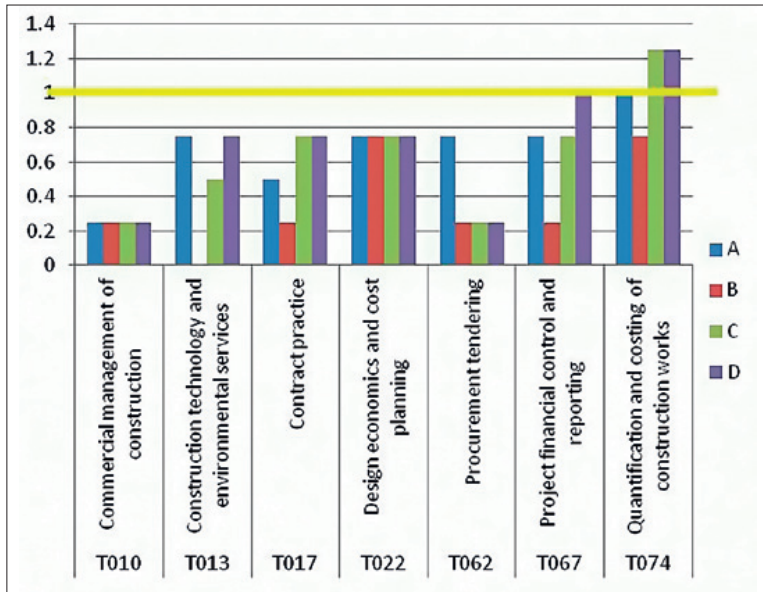

Figure 5. Core competency mapping scores: Level 2

cies. However, as a cumulative score is used this may not fully represent the required level of achievement of a competency.

Figure 5. Core competency mapping scores: Level 2 indicates the core competency coverage at Level 2. It is clear that set against a benchmark score of 1 there is inadequate coverage for all competencies across all universities except for T074 Quantification and Costing of Construction works. The scoring for mapping was carried out based primarily on scoring by programme leaders. In the absence of a detailed specification to indicate what level of content coverage is required for a competency to be achieved, it is difficult to have a uniformly interpreted outcome.

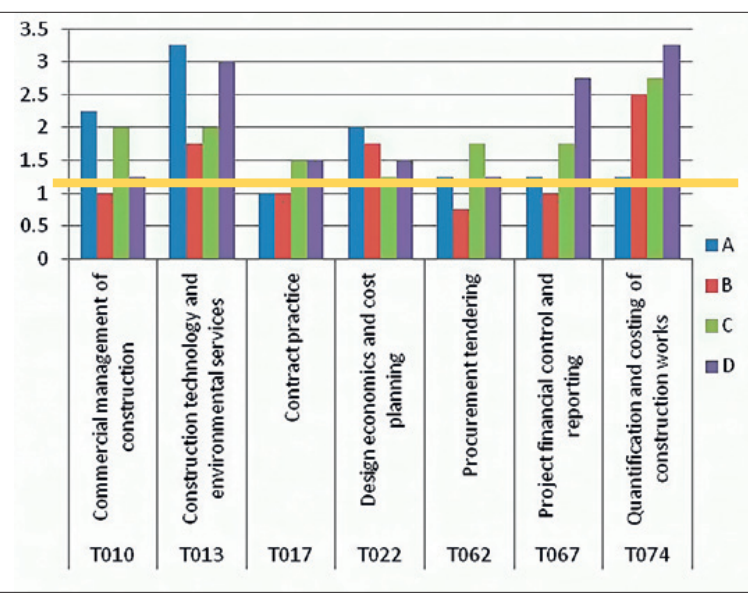

Figure 4. Core competency mapping scores: Level 1

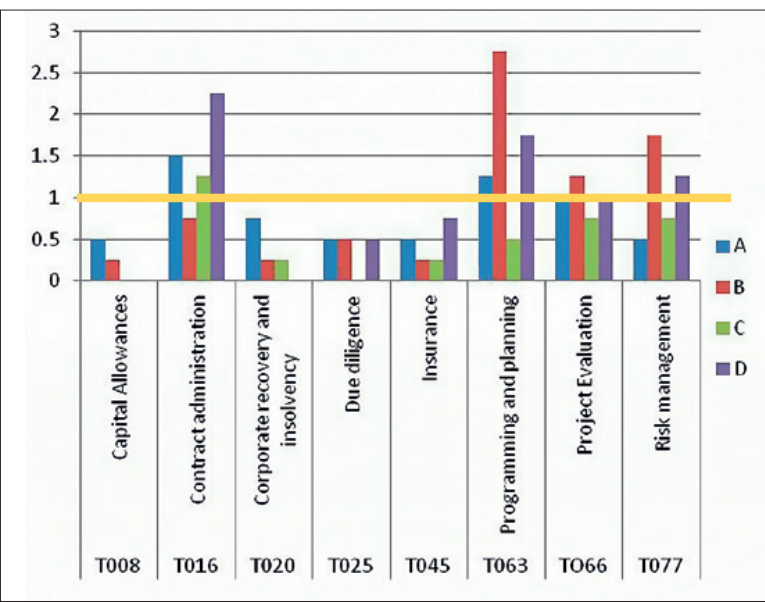

Figure 6. Optional competency mapping scores: Level 1

\subsubsection{Coverage of optional competencies}

Only two Optional competencies are required to be addressed for the APC. However, universities attempt to cover many optional competencies in their curricular often as non-optimal modules. There is no guidance from the RICS as to how many or to what extent (which level) these optional competencies should be completed upon graduation. This is again open to interpretation.

Figure 6. Optional competency mapping scores: Level 1 clearly indicates that all universities do not achieve optional competencies to a benchmark level score of 1 . 


\section{VIEWS OF THE EXPERT FORUM}

\subsection{Expected achievement of mandatory, core and optional competencies}

The RICS QS competencies provide the basis on which a quantity surveyor will be judged as to their capability to act as an independent, professionally qualified chartered surveyor. The respondents were first asked to consider the competencies in general. The RICS representative noted that there are more prescribed core competencies for QS than for any other pathway. This was however to be combined with the understanding that not every competence need be met by the universities and that the RICS welcomed diversity to reflect the individual strengths of each. Industry CQS respondents noted that the competencies were relevant and "do adequately describe what we want".

A summary of expected level of competency is presented in Table 4. These were extracted from 8 expert forum members who responded to this section. They include 3 academics, 3 CQS and 2 PQS. Also, not all the 8 respondents have graduate level expectation for some Optional competencies such as Capital allowances, Corporate recovery and insolvency, Due diligence and Programming and planning.

The RICS stipulates that an APC candidate needs to achieve all Mandatory competencies at Level 2 or above. Table 4 shows that some of the experts expect graduate QS to have achieved Mandatory competencies at Level 2 or even Level 3. For some competencies such as Communication and negotiation, Data management, and Teamworking, this may be expected due to hypothetical projects and multidisciplinary projects modules involving simulations in most QS degree programmes. But for other competencies such as Business planning, Client care, conduct rules, ethics and professional practice, Health and Safety, etc. it is difficult to see how graduate QS can achieve this through university education.

Table 4 also revealed that most Core competencies are expected to be achieved at Level
2 by graduate QS. It is however worrying that certain academics think that core QS skills such as Design economics and cost planning, Quantification and costing of construction works, etc. should be achieved to Level 1 despite possibilities for learning at Level 2. More worrying is the expectation of a few industry experts who think that graduate QSs should have achieved Level 3 in Commercial management of construction, Construction technology and environmental services, Contract practice, Design economics and cost planning and Quantification and costing of construction works. The RICS stipulates that an APC candidate needs to achieve all Core competencies at Level 3 (except one not relevant to specialisation depending on employment in consulting or contracting practice which is at Level 2). To gain relevant experience and skills, an APC candidate must have worked for 3 years after graduation. Hence it is difficult to see how graduate QSs will have achieved Level 3 as some of the experts anticipated.

Furthermore, the RICS stipulates that an APC candidate needs to achieve two Optional competencies at Level 2 or above in the areas of specialisation. Table 4 shows the experts' expected level of achievement of Optional competencies by graduate quantity surveyors at mainly Level 1 and 2. Whilst the expectation at Level 2 is questionable, it is interesting to see four experts aiming for Level 3 in Contract administration and Programming and planning. The stated competencies are however popular specialisation areas for PQS and CQS respectively hence this is partly expected.

In conclusion, Table 4 shows that there is disparity in the expected level of competency. When viewed in relation to the mapping case studies, there appears to be inconsistency of views of the major construction stakeholders. There are indeed different interpretations of graduate level competency and actual attainment perhaps due to individual understanding of competencies, level definitions and the role of universities in the training of quantity surveyors. 
Table 4. Summary of expected level of graduate competency

\begin{tabular}{|c|c|c|c|c|c|c|}
\hline Competency & Code & Name & Level 1 & Level 2 & Level 3 & Comments \\
\hline Mandatory & M001 & $\begin{array}{l}\text { Accounting } \\
\text { principles and } \\
\text { procedures }\end{array}$ & 6 & 2 & & $\begin{array}{l}\text { Pure financial statement knowledge as } \\
\text { used in accounting is dealt with at a level } \\
1 \text { and } 2 \text {, but not certainly at Level } 3 \text {. }\end{array}$ \\
\hline Mandatory & M002 & $\begin{array}{l}\text { Business } \\
\text { planning }\end{array}$ & 7 & & 1 & $\begin{array}{l}\text { Several management modules applicable } \\
\text { and this is tending towards Level } 3 .\end{array}$ \\
\hline Mandatory & M003 & Client care & 3 & 4 & 1 & $\begin{array}{l}\text { This area is certainly covered up to } \\
\text { level } 2 \text { and it is tending to reach Level } \\
3 \text { due to hypothetical projects and multi } \\
\text { disciplinary projects (MDPs). }\end{array}$ \\
\hline Mandatory & M004 & $\begin{array}{l}\text { Communication } \\
\text { and negotiation }\end{array}$ & 3 & 4 & 1 & $\begin{array}{l}\text { Management modules, multidisciplinary } \\
\text { modules tending to Level } 3 .\end{array}$ \\
\hline Mandatory & M005 & $\begin{array}{l}\text { Conduct rules, } \\
\text { ethics and } \\
\text { professional } \\
\text { practice }\end{array}$ & 5 & 2 & 1 & $\begin{array}{l}\text { A "nice to have": This is covered up } \\
\text { to Level } 2 \text { within the project work for } \\
\text { professional practice and it is tending to } \\
\text { Level } 3 \text { in the MDP. }\end{array}$ \\
\hline Mandatory & M006 & $\begin{array}{l}\text { Conflict } \\
\text { avoidance, } \\
\text { management } \\
\text { and dispute } \\
\text { resolution } \\
\text { procedures }\end{array}$ & 3 & 5 & & $\begin{array}{l}\text { Procurement and admin, professional } \\
\text { practice at Level } 2 \text { and there is no } \\
\text { evidence of Level } 3 \text { completion for this } \\
\text { item. }\end{array}$ \\
\hline Mandatory & M007 & $\begin{array}{l}\text { Data } \\
\text { management }\end{array}$ & 1 & 5 & 2 & $\begin{array}{l}\text { Data and information management, } \\
\text { discipline projects within the final year } \\
\text { dissertation, there is evidence of tending } \\
\text { to Level } 3 \text {. }\end{array}$ \\
\hline Mandatory & M008 & $\begin{array}{l}\text { Health and } \\
\text { safety }\end{array}$ & 3 & 4 & 1 & $\begin{array}{l}\text { Not as a core module but the competencies } \\
\text { are delivered as parts of modules - law } \\
\text { and regulatory frameworks, construction } \\
\text { technology etc. }\end{array}$ \\
\hline Mandatory & M009 & Sustainability & 6 & 2 & & $\begin{array}{l}\text { Environmental services in Level } 1 \text { and } \\
\text { other technology modules tending to } \\
\text { Level } 2 \text { competency. This area needs } \\
\text { development up to Level } 3 \text { and important } \\
\text { to shape up the future role of the QS. }\end{array}$ \\
\hline Mandatory & M010 & Teamworking & 2 & 4 & 2 & $\begin{array}{l}\text { Aspects of many modules and specifically } \\
\text { MDPs. Therefore tending to Level } 3 .\end{array}$ \\
\hline Core & T010 & $\begin{array}{l}\text { Commercial } \\
\text { management of } \\
\text { construction }\end{array}$ & 2 & 5 & 1 & $\begin{array}{l}\text { Construction economics, procurement and } \\
\text { admin, estimating and tendering - some of } \\
\text { the assessments are tending to Level } 3 .\end{array}$ \\
\hline Core & T013 & $\begin{array}{l}\text { Construction } \\
\text { technology and } \\
\text { environmental } \\
\text { services }\end{array}$ & 2 & 5 & 1 & Level 1 mainly and Level 2. \\
\hline Core & T017 & Contract practice & 3 & 4 & 1 & Up to Level 2 only. \\
\hline Core & T022 & $\begin{array}{l}\text { Design } \\
\text { economics and } \\
\text { cost planning }\end{array}$ & 3 & 4 & 1 & For PQS's only; up to Level 2 only. \\
\hline Core & T062 & $\begin{array}{l}\text { Procurement } \\
\text { tendering }\end{array}$ & 2 & 6 & & Up to Level 2 only. \\
\hline
\end{tabular}




\begin{tabular}{|c|c|c|c|c|c|c|}
\hline Competency & Code & Name & Level 1 & Level 2 & Level 3 & Comments \\
\hline \multicolumn{7}{|l|}{ (Continued) } \\
\hline Core & T067 & $\begin{array}{l}\text { Project financial } \\
\text { control and } \\
\text { reporting }\end{array}$ & 2 & 6 & & Up to Level 2 only. \\
\hline Core & T074 & $\begin{array}{l}\text { Quantification } \\
\text { and costing of } \\
\text { construction } \\
\text { works }\end{array}$ & 2 & 2 & 4 & $\begin{array}{l}\text { Estimating and tendering at Level 1, } \\
\text { measurement under Level } 2 \text { and civil } \\
\text { engineering surveying at Level } 3 \text {. }\end{array}$ \\
\hline Optional & T008 & $\begin{array}{l}\text { Capital } \\
\text { Allowances }\end{array}$ & 5 & 1 & & $\begin{array}{l}\text { A "nice to have"; not sure about this. This } \\
\text { is usually a taxation subject; And other } \\
\text { allowances i.e. land remediation relief. }\end{array}$ \\
\hline Optional & T016 & $\begin{array}{l}\text { Contract } \\
\text { administration }\end{array}$ & 3 & 3 & 2 & $\begin{array}{l}\text { This is tending towards Level } 3 \text {; This } \\
\text { should be a core competency. }\end{array}$ \\
\hline Optional & T020 & $\begin{array}{l}\text { Corporate } \\
\text { recovery and } \\
\text { insolvency }\end{array}$ & 5 & 2 & & $\begin{array}{l}\text { This area may be touched upon under } \\
\text { financial management. Therefore tending } \\
\text { towards Level } 2 \text {. }\end{array}$ \\
\hline Optional & T025 & Due diligence & 6 & 1 & & A "nice to have"; professional practice. \\
\hline Optional & T045 & Insurance & 8 & & & $\begin{array}{l}\text { As I mentioned, this is an area that needs } \\
\text { development for the future of the QS. }\end{array}$ \\
\hline Optional & T063 & $\begin{array}{l}\text { Programming } \\
\text { and planning }\end{array}$ & 3 & 2 & 2 & For Contractors' QS's only; all 3 Levels. \\
\hline Optional & T077 & $\begin{array}{l}\text { Risk } \\
\text { management }\end{array}$ & 6 & 2 & & $\begin{array}{l}\text { There is wider coverage of the risk and } \\
\text { value management in Level } 3 \text { of the } \\
\text { course and in terms of competencies it will } \\
\text { be at Level } 2 \text {. }\end{array}$ \\
\hline
\end{tabular}

\subsection{Future role of the quantity surveyor}

The interviewees were requested to provide views on the present and future role of the QS. With respect to the present role of the QS they generally agreed that this centred on cost advice, estimating, and measurement. One academic noted that this differed between a contractor's surveyor and a consultant's surveyor though others did not stress the difference. There was some disagreement as to the development of the role of the QS. One PQS noted the role had not changed much whereas one CQS noted it had changed a lot.

\subsection{Perception of areas of work becoming more important}

There was a strong feeling that the role would become more complex, taking more concepts such as sustainability and whole life costing into account. One PQS stated "We are looking at WLC (the whole life cycle) of the facility and its use in a wider context". The importance of WLC was noted by two respondents, one CQS and one PQS. Two respondents (PQS and CQS) suggested that the name QS should change to reflect the function more accurately on the lines of Cost Manager or Cost Engineer. The name change is indicative of observations by other respondents that the difference between PQS and CQS is narrowing and the two roles are merging. The respondents in general indicated the need to up skill the QS knowledge base in use of ICT and its impact on the profession. They also agreed that collaboration and team working would be a more important skill to develop. Sustainability and project management skills were seen as areas for further development whilst civil engineering construction, infrastructure development and mechanical and electrical (energy related) projects were seen as growth sectors for the future.

One PQS was of the view that there is potential for procurement to revert to more traditional methods due to economic pressures. This could be seen as an important possibility that further enhances the cost control role of the QS. 


\subsection{Relative importance of the QS competencies}

Four respondents (three CQS, one PQS) noted that there were areas that were not given enough attention or that the students had poor knowledge of; valuation (1), measurement (1), building contracts (1), construction technology (2), $\mathrm{M}$ and $\mathrm{E}$ services (1), environmental services (1), team working (1), and data management (1).

When queried about possible additional competencies, three respondents (1 PQS, 1 RICS and 1 CQS) identified sustainability, business management and planning, accounting, communication (language, report writing and team working), new building technologies, pre-fabrication, civil and infrastructure engineering, life cycle costing as possible additional competencies. Some of these are already covered in some competencies. Since competencies do not give lengthy descriptions of content, these are open for interpretation.

Three respondents (2 academic, 1 CQS) were happy with the coverage and felt that there should be no new additions to the competencies/skills. One PQS stated that contract administration is listed as optional but felt that it should be core. No respondents felt that there was any obsolete content taught.

\subsection{Views on quantity surveying education}

Six respondents shared their views on the present nature of QS education (1 RICS, 2 academics, 2 PQS, 3 CQS). As class sizes get bigger to make courses more economically viable opportunities for tutors to spend more contact time and give more feedback will be compromised by the numbers of students they have to work with.

One PQS expressed the view that there was too much mass teaching, with a mismatch where the learning outcome does not map to the industry requirement and also felt that some lecturers need to update their knowledge so that the graduates were appraised of the latest techniques. The respondent did however note that it was not possible to make generalisations and there were differences between universities and individual lecturers. One PQS also felt that the RICS had less than adequate involvement in regulating curricular while another CQS felt that although there are many RICS accredited programmes they were not comparable in most respects.

\subsubsection{Level of satisfaction with the curriculum used to produce graduate QS}

The academic curricular content was commented on by 5 respondents (1 academic, 1 PQS, 3 CQS). The academic noted that they were able to cover a lot of the core competencies in a 4 year degree and that they could map modules that they teach to the core competencies. 2 respondents (1 PQS, 1 CQS) stated that the coverage was pretty good in general terms. However, the industry respondents felt that it was difficult to map modules taught at universities to RICS competencies.

One PQS felt that some courses do not deliver what employers want and one academic stated "students are going out without the necessary skills to undertake their basic job and that is where employees feel that the universities are letting the system down". This being said, the general view was that it is not easy to generalise and some courses are better than others and also it is down to other factors such as the student, mode of study, and employer.

\subsubsection{Views on QS programme curriculum development}

On aspects of curricular development 5 interviewees responded. Two identified measurement as an area that needs greater attention (1 CQS, 1 PQS). Other areas identified include taxation (CQS), understanding building technology and construction (CQS), bill of quantities (PQS), cost planning, preconstruction estimating (CQS) while there was an overemphasis on management of projects (1 PQS, 1 CQS).The aspect that caused most concern for one PQS was that graduates had a poor understanding about construction technology and no real understanding of on-site con- 
ditions. Reflecting on these views it is clear that greater attention is needed to some core areas of quantity surveying. If so, the academics will be faced with the dilemma of identifying which areas to forego in lieu of areas of expansion.

\subsubsection{The role of universities in producing a graduate quantity surveyor}

All 10 respondents considered what a university should provide with regards to QS education. They were requested to choose between:

1. Provide an overall academic knowledge and a good foundation in Quantity Surveying, or

2. Concentrate on training students for direct QS employment.

Six respondents agreed with statement 1 (2 PQS, 1 CQS, 1 RICS, 2 academics). 2 respondents agreed with statement 2 (1 PQS, 1CQS). One CQS felt that it should be a bit of both, a balance of academia with vocational on a 50/50 basis. One academic was undecided. One CQS stated that over the last 30 years they have seen the quality of technical Quantity Surveying become diluted and warned that if the trend continues we would lose technical standards forever.

In overall terms most wished to see a sound academic background for graduate quantity surveyors but did not want to see any compromise on the level of knowledge. They also seem to expect improved technical competence in graduates going into the industry.

\subsubsection{Industry - academia collaboration in QS programme delivery}

Two respondents (1 PQS, 1 CQS) commented that there is a reasonable level of employer engagement with the universities. However, the level and extent of engagement is one aspect that requires further exploration.

\subsubsection{Industry - academia level of communication}

Communications between universities and industry were generally seen to be reasonable although it was added that universities try the hardest and industry needs to be better at communication. The state of the economy was seen as a factor that influences level of communication (1 academic). Greater involvement of the industry as a stakeholder in the development of programmes, face to face industry consultation and industry taking programme development and contributions as part of their corporate social responsibility were seen as steps that can be used to improve the situation.

\subsection{Modes of study and industry placement}

\subsubsection{Perceived success of modes of study}

The majority of respondents (9) stated that Part Time students were far better and more rounded than full time students, though this was usually in respect of their dedication to work and approach to the job.

\subsubsection{Industry placement in quantity surveying education}

All 10 interviewees had contributions to make concerning their views on placement. This was unanimously seen as a positive, if not crucial, thing for a student to have. The experience the student gains from having practical experience cannot be replicated in any other way. The current economic situation is having a negative impact on the availability of placements.

\subsection{RICS membership routes and training}

\subsubsection{Routes of membership}

The RICS QS competencies (learned through education and industry experience) provide the basis on which a quantity surveyor will be judged as to their capability to act as an independent professionally qualified chartered surveyor. Graduate QS can become professionally qualified upon successful completion of the APC after 3 years of post-qualification industry experience. The graduate route is still apparently the most popular route to chartered membership. It is expected to breach the gap 
between what is learnt at university and what is needed to get chartered. As a result, it is useful to investigate the appropriateness of this membership route and others.

The RICS recently revised their membership pathways.

\subsubsection{Level of awareness}

Accordingly, two interviewees (1PQS, 1CQS) stated that they are not familiar with the new routes of membership other than the graduate route.

\subsubsection{The appropriateness of routes of membership}

A total of seven (1 RICS, 2 academic, 2 PQS, $2 \mathrm{CQS}$ ) expressed content with the graduate route of membership. One CQS did note that it was sometimes hard to push graduates into becoming chartered, suggesting that this was due to a combination of fee levels and their not seeing any advantage in becoming chartered. Another problem that exists is that more specialised contractors did not give the graduate a wide enough experience in some competencies (1 academic, 1 RICS).

The new Associate pathway was stressed as not being a shortcut to becoming chartered surveyor by the RICS representative. One academic said that it was a nice idea but did not see its relevance and felt that it was not clear enough where the cut off point was between the two levels while another expressed some reservations. One PQS felt that it may lead to people aiming for a minimum standard and that AssocRICS is not good enough to be recognised. 1 CQS noted that it was helpful to people who do not have degrees but to then progress to MRICS or FRICS was a very convoluted route. Another CQS said their company had looked at this route but gone back to the graduate route. These sentiments suggest there is lack of understanding about the new route as well as some doubt as to the need for it.

There was a mixed response to the new Senior Professional route. Three respondents stated that they were not happy with this route. 1 academic viewed it as a "rubber stamping" exercise. One CQS said "my main problem with that route is that it does not test techni- cal competence". One PQS did not think that people should just be given MRICS for their long experience and although it provides an opportunity to get practitioners into mainstream RICS, they should still fit the APC model and competencies. One academic warned that the RICS have to be careful not to be seen as an institution desperate to get new members in. On the positive side, one PQS noted that it was good and had worked well for them, adding that the CIOB are doing the same thing.

\subsubsection{Availability and importance of a structured training programme for APC}

The RICS representative noted that unless the company has signed up to the structured training programme they should not take on a graduate for APC. Three respondents (2 CQS, 1 PQS) stated that they did have a structured training programme. One PQS noted that there were very low completion rates for the APC and felt that this was due to very poor levels of basic knowledge, with big gaps between what is learnt at university and what is needed to get chartered. One possible reason for this was seen as employers not considering it as important and that they lack a structured training programme. It was also noted that it is difficult to provide all the training in three years. Smaller companies often struggle as they do not have the volume or frequency of work types to enable them to have a smooth training process. One PQS was highly critical of the APC process itself, stating that it is a daunting process that makes candidates unduly nervous. The RICS process compares with the CIOB less favourably as the CIOB process is friendlier and they help you to get through it.

\subsection{Views on the role of RICS}

\subsubsection{Level of communications with the RICS}

The level of communication and the respondents' perception was analysed with respect to RICS Partnerships for programme accreditation, the RICS and Universities, the RICS and Industry communication, Industry and Universities communication. 
With specific reference to the communication between the RICS and universities 4 respondents (2 academic, 1 CQS, 1 PQS) made contributions. The 2 academics noted that they had a good rapport with the RICS. The CQS did not know about this while the PQS thought that some had good communication with the RICS and others did not.

The general consensus with respect to communications between the RICS and industry was that it is in need of much improvement, although it is beginning to move in the right direction. There is a need for increase in regional and local level of involvement (2 academic), fees scales need to be more realistic (1 PQS), and RICS needs to be more in touch with leading edge work (1 PQS). Three respondents (1 PQS, 2 CQS) did not really have any contact with RICS through their role in the company with one commenting that RICS has lost its focus on members and become a business instead of an Institution (CQS).

\subsubsection{Level of success of the RICS - university partnership agreement}

The RICS partnership process was seen as facilitating greater discussion, but most communications still came down to personal relationships. One academic saw the accreditation partnership as a way to understand how the course is being assessed "so that students come out with the ability to be Quantity Surveyors". These indicate the primary role of the RICS partnership agreement as regulating RICS accredited programmes. However, the level and detail of regulation was criticised. One PQS felt that there was a conflict of interest within the RICS Education Board if there were academic members on the board and these influenced its decisions. But, this is questionable as the role of Board is not necessarily to project the view of industry alone. A balanced representation perhaps might be useful. Lack of consultation with the professional group was also noted adding that RICS communication with industry was not good. One CQS did not know about the partnership arrangements. Another felt that there was a real inertia around working out solutions to problems that were identified. There was recognition of the difficulty involved in getting all three parties around the table and keeping the lines of communication open.

\section{DISCUSSION}

The research aimed at investigating the changing developmental needs of Quantity Surveyors who satisfy the aspirations of industrial, professional and academic stakeholders. It used several research instruments to achieve this:

1. Review of RICS QS competencies: provides details of competencies.

2. Competency mapping cases studies involving 4 RICS accredited QS honours degree programmes: indicates how competencies are mapped to programme curricular.

3. Expert views from a forum of experts (industry, academic and the RICS): enlightens on level of competency to be achieved by a graduate and other contextual factors.

The main research objectives sought to ascertain several key aspects related to QS education and development. These are summarised in the following sections.

\subsection{Summary of the status of RICS QS competencies}

The RICS has formulated clear and detailed documentation (RICS, 2009) identifying, classifying and explaining QS competencies. This is primarily aimed at providing guidance to APC candidates seeking full professional membership of the institution. There are $24 \mathrm{QS}$ competencies classified as Mandatory (10), Core (7) and Optional (7). These competencies can be achieved at any of three levels as Level 1, 2 or 3. The RICS defines that an APC candidate needs to achieve all Mandatory competencies at Level 2 or above, all Core competencies at Level 3 (except one not relevant to specialisation depending on employment in consulting or contracting practice which is at Level 2) and two Optional competencies at Level 2 or above. 
These competencies form the basis for describing the knowledge-base of the quantity surveyor and at APC to ascertain the level of attainment. Therefore, they should form the basis on which QS degree programme curriculum is modelled. At each programme accreditation the RICS seeks to establish whether the programme in question deals with these competencies. There is no systematic approach or guidance as to what level of competency need be achieved by a graduate completing a RICS accredited programme. At present it is an estimation of whether core competencies are addressed in module specifications.

This process has led to RICS accredited honours degree programmes across the country producing graduates demonstrating considerably varying degrees of competence. It is then left to the employers and graduates themselves to up skill to the required benchmark specified for the APC. What was clearly found in this research is that this process produces a graduate less confident to face the industry and an employer less satisfied than they might otherwise be. This clearly confirms the findings of Lee and Hogg (2009).

\subsection{Key findings of competency mapping}

The main findings related to the competency mapping can be summarised as follows:

1. There is no prescribed threshold benchmark standard for achieving competencies at graduate level.

2. There are no detailed specifications to indicate what content should be covered to achieve a competency.

3. Different universities aim to achieve competencies at different levels, based on their own interpretations.

4. In the absence of a detailed competency specification, the level of achievement of competencies as judged by our own interpretation seems satisfactory for the most part. There are inadequacies in the level of coverage of some competencies.

5. Programme leaders tend to interpret levels of achievement of competencies differently to one another, resulting in apparent differing levels of achievement of competencies and different levels of coverage.

6. There is no standard way to interpret the actual achievement of competencies.

7. There is no formal competency mapping process available for universities in curricular development or revision.

8. Most mandatory competencies are not achieved to a significant extent by the universities studied to date.

9. Core competencies are well achieved at Level 1 based on interpretations made by universities and some attempt made at Level 2. There is greater scope for achieving core competencies to some extent at Level 2.

10. Optional competencies are not reasonably achieved at Level 1 by most universities. Some competencies are however dealt with to a considerably higher level by some universities. There is greater variation across universities.

\subsection{Views of the expert forum}

Most experts were of the opinion that competencies in general should be achieved at Level 1 by graduates. However, some academic experts were of the view that universities achieve more than Level 1 in some competencies and move greatly towards Level 2. One Consultant QS was of the view that both Mandatory and Core competencies should be achieved at Level 2.

The above situation is exactly reflected with respect to the coverage of competencies. There is no uniform view and it is very much open to individual interpretation. These tensions of interpretation are well evident in the above competency mapping case study analysis.

\section{CONCLUSIONS}

The development needs of quantity surveyors are highly influenced by the needs of the industry and profession and shaped by the perception of academia that produces QS graduates to the profession. This research analysed RICS QS competencies and how they are mapped against degree programmes 
that produce QS graduates. It revealed that there is a huge variation in interpretation of competencies and levels of achievement. The documentation available is inadequate for this purpose probably because it is intended for APC candidate guidance. The competency mapping case studies revealed that there is a high level of variation in the mapping of competencies between programmes especially at Level 1. Although based on the views of programme directors the mapping indicated that most core competencies are well mapped but that there are deficiencies in mandatory and optional competencies. The net result is that there is significant variation in the quality and level of graduates produced by different degree programmes accredited by the RICS. This problem is exacerbated as the programme directors as well as industry experts have considerably varying degree of interpretation of competencies.

The absence of a threshold benchmark that clearly defines graduate level of competence has led the industry to have unrealistic expectations; academia to aspire for unattainable levels of competence, producing a less than satisfied graduate that defies direction.

The expert forum was also used to extract contextual factors that influence industrial, professional and academic development of QS graduates. Overwhelming majority of the expert forum was of the view that the aim of universities' should be to provide an overall academic knowledge and a good foundation in Quantity Surveying as opposed to provide training to produce a QS for the industry.

\subsection{Limitations}

The analysis of competencies was limited to the documents currently available for download from the RICS web portal. The mapping of competencies was limited to opinions of the programme directors moderated through cursory examination of module specifications. Therefore it is possible that there could be a reasonable degree of variation in the outcome of mappings. But the authors are of the opinion that this would not be to an extent that would undermine the overall conclusions derived for the project.

\subsection{Further research and directions}

The focus of the research was to evaluate the views of the two main stakeholders of graduate QS education; the universities and industry. The universities were represented by academics responsible for programme delivery while the industry was represented by consultant (PQS), contractor or commercial (CQS). The views of these stakeholders on the relationship with the RICS were also investigated. There is a considerable degree of differing views and lack of responsibility from all stakeholders, mainly arising out of inaccurate interpretations and lack of definition. This lack of a common benchmark for the interpretation of achievement of competencies by graduates clearly contributes to the dissatisfaction and false expectations on the part of the industry and thus the demoralisation of the graduate. In order to address this situation and thereby align the disparate views of industry, academia and the RICS, further research in the development of a Graduate Competency Threshold Benchmark and the Competency Mapping Framework will be required.

\section{REFERENCES}

Bowen, P., Cattell, K., Distiller, G. and Edwards, P. J. (2008) Job satisfaction of South African quantity surveyors: An empirical study, Construction Management and Economics, 26(7), pp. 765-780. http:// dx.doi.org/10.1080/01446190801998724

Cartlidge, D. (2006) New aspects of quantity surveying practice. $2^{\text {nd }}$ ed. Butterworth Heinemann.

Cowan, D. T., Norman, I. and Coopamah, V. P. (2007) Competence in nursing practice: A controversial concept - A focused review of literature, Accident and Emergency Nursing, 15(1), pp. 20-26. http://dx.doi. org/10.1016/j.aaen.2006.11.002

Davis Langdon and Everest (1991) Quantity surveying 2000. UK: Royal Institution of Chartered Surveyors (RICS).

Ewens, T. (1979) Transforming a liberal arts curriculum: Alverno College. In: Grant, G., et al. (ed.), On competence: A critical analysis of competence-based reforms in higher education. San Francisco: JosseyBass, pp. 259-298.

Fan, L. C. N., Ho, C. M. F. and Ng, V. C. M. (2001a) A study of surveyors' ethical behavior, Construction Management and Economics, 19(1), pp. 19-36. http:// dx.doi.org/10.1080/014461901452058 
Fan, L. C. N., Ho, C. M. F. and Ng, V. C. M. (2001b) Effect of professional socialization on quantity surveyors ethical perception in Hong Kong, Engineering, Construction and Architectural Management, 8(4), pp. 304-312. http://dx.doi.org/10.1108/eb021191

Fellows, R., Liu, A. and Fong, C. (2003) Leadership style and power relations in quantity surveying in Hong Kong, Construction Management and Economics, 21(8), pp. 809-818. http://dx.doi. org/10.1080/0144619032000174521

John, W. (2002) Challenges for the quantity surveying profession in the light of new developments, The Surveyor, 4, pp. 19-23.

Lee, C. C. T. and Hogg, K. (2009) Early career training of quantity surveying professionals. In: Proceedings of the RICS COBRA research conference, University of Cape Town, South Africa, 10-11 September 2009.

Ling, F. Y. Y. and Chan, A. H. M. (2008) Internationalising quantity surveying services, Engineering, Construction and Architectural Management, 15(5), pp. 440455. http://dx.doi.org/10.1108/09699980810902730

Lowe, D. and Leiringer, R. (2006) Commercial management of projects: Defining the discipline. Blackwell Publishing.

Male, S. (1990) Professional authority, power and emerging forms of 'profession' in quantity surveying, Construction Management and Economics, 8(2), pp. 191204. http://dx.doi.org/10.1080/01446199000000016

Maidin, A. J. and Sulaiman, S. S. (2011) Importance of legal education for quantity surveying professionals: A proposal for developing a legal studies module for Malaysian system, Journal of Applied Sciences Research, 7(13), pp. 2249-2256.

Meyer, T. and Semark, P. (1996) A framework for the use of competencies for achieving competitive advantage, South African Journal of Business Management, 27(4), pp. 96-103.

Mole, G., Plant, R. and Salaman, G. (1993) Developing executive competencies: Learning to confront, confronting to learn, Journal of European Industrial Training, 17(2), pp. 3-7. http://dx.doi. org/10.1108/03090599310027138

Newton, S. (2009) Transformational higher education in the built environment, Journal for Education in the Built Environment, 4(1), pp. 100-112. http://dx.doi. org/10.11120/jebe.2009.04010100

Pathirage, C. P. and Amaratunga, R. D. G. (2006) A vision for the quantity surveying education in the $21^{\text {st }}$ century: United Kingdom perspective. In: Custom ising the quantity surveying education, Department of Building Economics, University of Moratuwa, Sri Lanka.

Perera, R. S. (2006) Views of prospective graduate surveyors on their professional career plans. Final report, RICS NI, August 2006.

Perera, S. and Pearson, J. (2011) Alignment of professional, academic and industrial development needs for quantity surveyors: Post recession dynamics. [Online] RICS Education Trust funded research report, UK. Available at: http://www.northumbria-qs.org/RICS_
Alignment/Reports/Alignment_of_views_final_report. pdf [accessed 25 October 2011]

Pheng, L. S. and Ming, K. H. (1997) Formulating a strategic marketing mix for quantity surveyors, Marketing Intelligence \& Planning, 15(6), pp. 273-280. http:// dx.doi.org/10.1108/02634509710184857

Rashid, K. A. (2002) A study on the curricula for the bachelor of quantity surveying courses in Malaysia, The Surveyor, 3, pp. 17-22.

Rick, B. (2005) How much measurement is enough? Quantity surveying education in Australia, The Building Economist, pp. 16-20.

RICS (1971) The future role of the quantity surveyor. RICS.

RICS (1983) The future role of the chartered quantity surveyor. RICS.

RICS (2009a) RICS employability threshold consultation document: Letter to partner institutions. RICS, October 2009.

RICS (2009b) Requirements and competencies, RICS education and qualification standards. [Online] RICS. Available at: http://www.rics.org/site/scripts/download_info.aspx?fileID=3729\&categoryID $=98$ [accessed 2010].

Rowe, G. and Wright, G. (2001) Expert opinions in forecasting: Role of the Delphi technique. In: Armstrong, J. S. (ed.), Principles of forecasting: A handbook of researchers and practitioners. Boston: Kluwer Academic Publishers, pp. 125-144.

Senaratne, S. and Sabesan, S. (2008) Managing knowledge as quantity surveyors: An exploratory case study in Sri Lanka, Built-Environment Sri Lanka, 8(2), pp. 41-47.

Simpson, Y. (2010) Twenty first century challenges for the professional quantity surveyor. In: Proceedings of the RICS COBRA 2010 conference, Dauphine Université, Paris.

Smith, P. (2009) Trends in the Australian quantity surveying profession: 1995-2008. In: Proceedings of the $13^{\text {th }}$ Pacific Association of Quantity Surveyors Congress (PAQS 2009), 17-18 August 2009, Kuala Lumpur, pp. 22-32.

Trivett, D. A. (1975) Competency programs in higher education. ERICI Higher Education Research Report No. 7. Washington, D.C.: American Association for Higher Education, (ED 118 023).

UNN Returns (2001-2008) UNN returns. Annual $1^{\text {st }}$ Destination returns from the University of Northumbria to RICS Partnership Accreditation Board 2001-2008.

Walker, I. and Wilkie, R. (2002) Commercial management in construction. Blackwell Publishing.

Wong, J. M. W., Wong, F. K. W. and Hui, E. C. M. (2007) A study to improve higher education for surveying professionals in Hong Kong, Journal for Education in the Built Environment, 2(1), pp. 76-89. http:// dx.doi.org/10.11120/jebe.2007.02010076 